\title{
Oxidants and Antioxidants in COPD Associated with Tobacco Smoke and Biomass Exposure
}

Sumanta Jha ${ }^{1}$, Debojyoti Bhattacharjee ${ }^{2}$, Subho Chowdhuri ${ }^{3}$, Apratim Mitra ${ }^{4}$, Abhradip Das $^{5}$, Kheya Mukherjee ${ }^{6}$

${ }^{1}$ Department of Pulmonary Medicine, Nilratan Sircar Medical College \& Hospital, Kolkata, West Bengal, India. ${ }^{2}$ Department of Biochemistry, Institute of Postgraduate Medical Education and Research and SSKM Hospital, Kolkata, West Bengal, India. ${ }^{3}$ Murshidabad Medical College and Hospital, Berhampore, West Bengal, India. ${ }^{4}$ Department of Pulmonary Medicine, Calcutta National Medical College and Hospital, Kolkata, West Bengal, India. ${ }^{5}$ Department of Pulmonary Medicine, Calcutta National Medical College and Hospital, Kolkata, West Bengal, India. ${ }^{6}$ Department of Microbiology, ID and BG Hospital, Kolkata, West Bengal, India.

\section{ABSTRACT}

\section{BACKGROUND}

Chronic Obstructive Pulmonary Disease (COPD) is one of the leading causes of chronic morbidity and mortality. Apart from tobacco smoke, biomass fuel has been implicated as an important etiological factor for development of COPD. Oxidantantioxidant imbalance is known to play a key role in pathophysiology of COPD. The study was undertaken to evaluate the role of oxidative stress and antioxidant status among COPD cases due to tobacco smoking and biomass exposure.

\section{METHODS}

Serum MDA, and erythrocyte SOD and GSH levels, were estimated among 40 COPD cases due to tobacco smoking (Group 1), 20 COPD cases due to biomass exposure (Group 2). 40 age and sex matched healthy controls (Group 0) were also included. Serum MDA, SOD and GSH were measured calorimetrically by TBA method, Marklund \& Marklund method and method by Beutler et al respectively.

\section{RESULTS}

IBM SPSS Ver. 20 was used for statistical analysis and preparation of tables. Significantly higher levels of MDA were seen among COPD cases due to tobacco smoke $(58.08 \pm 52$ vs $15.3705 \pm 6.6$; p value $<0.01$ ) compared to controls. SOD levels were significantly lower in both case groups compared to controls $(1123.3 \pm 301.2$, $1147.01 \pm 200.5$ vs $1315.23 \pm 209.1$; p value $<0.01$ ). GSH levels were lower in tobacco smoking group when compared to biomass exposed group (7.98 \pm 2.7 vs $9.61 \pm 2.1$; value 0.01). Positive correlation was found between FEV1\% and SOD in group 1 cases.

\section{CONCLUSIONS}

The results support the hypothesis of presence of increased oxidative stress and oxidant-antioxidant imbalance in pathogenesis of COPD. It plays an important role in disease severity which is higher among COPD in tobacco smokers compared to biomass exposed COPD.

\section{KEY WORDS}

COPD, Smoking, Biomass, Oxidants, Antioxidants

\begin{abstract}
Corresponding Author:
Dr. Debojyoti Bhattacharjee, Department of Biochemistry, Institute of Postgraduate Medical Education and Research and SSKM Hospital, Kolkata, West Bengal, India. E-mail: debojyoti1979@rediffmail.com
\end{abstract}

DOI: 10.14260/jemds/2019/747

Financial or Other Competing Interests: None.

How to Cite This Article:

Jha $S$, Bhattacharjee D, Chowdhuri S, et al. Oxidants and antioxidants in COPD associated with tobacco smoke and biomass exposure. J. Evolution Med. Dent. Sci. 2019;8(46):3449-3453, DOI: $10.14260 /$ jemds/2019/747

Submission 22-08-2019, Peer Review 02-11-2019, Acceptance 08-11-2019, Published 18-11-2019. 


\section{BACKGROUND}

Aetiology of COPD in India: Chronic obstructive pulmonary disease (COPD), a common preventable and treatable disease, is characterized by persistent airflow limitation that is usually progressive and is associated with an enhanced chronic inflammatory response in the airways and the lung to noxious particles or gases.[1] Exacerbations and co morbidities contribute to the overall severity in individual patients. Much of the increase in incidence of COPD is associated with projected increase in tobacco use and the indoor exposure to smoke from the combustion of solid biomass fuel, for heating and cooking.[2] Significantly ratios for COPD in India for both Male: Female and smoker: nonsmoker are not as high as in the Western populations. This is largely attributed to the indoor air pollution from domestic combustion of solid biomass fuels.[3],[4],[5] Commonly used solid biomass fuels for cooking are cow dung cake, wood and coal. Environmental tobacco smoke (ETS) from passive smoking mainly from male smokers in the house is also another important risk factor for COPD in non-smoker women. ${ }^{[3]}$

Cigarette smoke and inflammation: Oxidative stress has been attributed to play the central role in the pathogenesis of COPD. In addition to causing direct injury to the respiratory tract, oxidative stress triggers and exacerbates chiefly three other mechanisms namely inflammation, apoptosis and protease-antiprotease imbalance.[6],[7] Cigarette smoke contains approximately five thousand toxic compounds, including potent oxidants (Approximately 1014 free radicals per inhalation) such as acrolein, hydrogen peroxide $\left(\mathrm{H}_{2} \mathrm{O}_{2}\right)$, hydroxyl (OH.) and organic free radicals. ${ }^{[8]}$ Reactive oxygen species (ROS) directly recruit inflammatory cells such as neutrophils, eosinophils, lymphocytes and macrophages resulting in inflammation. [9] ROS cause overexpression of the genes of proinflammatory mediators (e.g. tumour necrosis factor $[\mathrm{TNF}]-\alpha$, interleukin[IL]-1, and interleukin[IL]-8) via transcription factor NF- $k b(N u c l e a r$ factor kappa B) and AP-1 (Activator protein-1), thus further recruiting inflammatory cells.[10] ROS can also form reactive aldehydes by lipid peroxidation of membrane phospholipids like 4-hydroxy-2nonenal (4HNE) and MDA (Malondialdehyde) which are capable of inducing caspase (A major promoter of cell apoptosis).[11]

Human biological antioxidants: In normal cell, there is an appropriate pro-oxidant: antioxidant balance. Indigenous compounds and reactions disposing of these species, scavenging them, suppressing their formation or opposing their actions are antioxidants and include compounds such as NADPH (Reduced nicotinamide adenine dinucleotide phosphate), GSH (reduced glutathione), ascorbic acid, vitamin E, superoxide dismutase (SOD), glutathione peroxidase (GPx) etc.[12] SOD and GSH associated enzymes are enzymatic antioxidants which are active at the beginning of reaction through which reactive species are formed, and this avoids accumulation of $\mathrm{O}_{2}$.- and $\mathrm{H}_{2} \mathrm{O}_{2}$.[13] There are three isomers of SOD, all neutralize superoxide. GSH is one of the primary non- enzymatic antioxidants in lung and exists in epithelial lining fluid, reduces $\mathrm{H}_{2} \mathrm{O}_{2}$ and lipid peroxides and neutralizes xenobiotic radicals.[14]

Effects of oxidative stress: Oxidative stress causes peroxidation of Polyunsaturated Fatty Acid (PUFA) present in cell membrane phospholipids. This leads to alteration in the structure and permeability of the cell membrane, resulting in loss of ion exchange selectivity, release of contents of organelles, i.e. hydrolytic enzymes of lysosome and formation of cytotoxic products such as MDA.[15]

\section{Measurements of Human Oxi-Antioxidants}

Oxidative stress can be measured through indirect quantification of products of lipid peroxidation like MDA, in the alveolar space, in the exhaled breath condensate, in the sputum and the blood.[16] Simultaneous estimation of antioxidant status can be made by measurement of serum levels of antioxidants like SOD, GSH.

\section{METHODS}

Place of study and patient selection: A total of 100 subjects including cases and controls had participated in the study. 60 stable COPD cases, none having acute exacerbation at the time of study, diagnosed clinically and confirmed with spirometry attending or admitted in Department of Pulmonary and Chest Medicine,Calcutta National Medical College and Hospital, Kolkata, West Bengal. Sample size was taken based on the convenience of the study. Approval from the institutional ethical committee was obtained for the study. The cases were divided into two groups based on current smoking history and history of exposure to biomass consisting of 40 (Group 1) and 20 (Group 2) cases respectively. Similarly, 40 age and sex matched healthy controls without history of smoking or biomass exposure were selected from persons who accompanied the patients and also from health care workers who participated voluntarily in the study (Group 0). Subjects with dual exposure to tobacco smoke and biomass were excluded from this study. Informed consent was obtained from all the subjects prior to the study.

Subject exclusion criteria and analyte estimation: Patients with pleural disease, malignancy of lung, tuberculosis, human immunodeficiency virus (HIV) infection, diffuse parenchymal lung disease (DPLD), diabetes mellitus, dyslipidemia, hypertension, connective tissue disorders, chronic renal or hepatic diseases were excluded from the study. Chest skiagram PA view, pulmonary function test (PFT) with bronchodilator reversibility were done in all cases and controls. About $6 \mathrm{ml}$ of blood was drawn from a large peripheral vein under aseptic precaution after overnight fasting with a heparinised syringe and was transported immediately to the laboratory, Department of Biochemistry, Calcutta National Medical College and Hospital. The sample was then centrifuged to separate serum and prepare RBC lysate. Serum MDA activity was measured in serum by thiobarbituric acid method.[17] SOD and reduced GSH activities were measured in RBC lysate by methods of Marklund and Marklund[18] and Beutler et al[19] respectively. 


\section{Statistical Analysis}

Statistical analysis was done with IBM SPSS Ver. 20. Chisquare test was performed to analyze the age and sex distribution pattern among cases and controls. Post-hoc ANOVA with and without Bonferroni correction was performed to estimate the statistical significance between variables like MDA, SOD and GSH among case groups and controls.

\section{RESULTS}

Age comparison among case groups and controls: The mean age distribution among COPD in smokers, COPD among biomass exposed and controls, selected for the study were close to each other as much as possible (Table 1) [Chi-square Test: $\mathrm{p}$-value $>0.068$, degree of freedom $=1$ ].

Comparison of MDA, SOD and GSH levels among case groups and controls: The mean \pm SD values for MDA, SOD, and GSH among the case groups (1 and 2) and controls (0) were represented in (Table 2). The values of MDA were significantly higher in Group 1 cases when compared to Group 0 (p-value < 0.001). No statistical difference was seen between cases and between Group 2 and Group 0. SOD levels were significantly lower among the case groups when compared to controls ( $p$ value $<0.05$ ). Higher level of GSH was found in biomass exposed COPD cases than COPD with smoking history ( $p$ value $<0.05$ ) (Table 3A, Table 3B).

Correlation between FEV1\% and various oxiantioxidants: In Group 1, FEV1\% was positively correlated to SOD value ( $p$ value $<0.015$ ). SOD and GSH values were also correlated to each other among smokers (Table 4). No similar correlation existed for FEV1\%, MDA, SOD and GSH among the group 2 cases and controls.

\begin{tabular}{|c|c|c|c|}
\hline Groups & $\begin{array}{l}\text { Group } 1 \\
(n=40)\end{array}$ & $\begin{array}{c}\text { Group } 2 \\
(n=20)\end{array}$ & $\begin{array}{c}\text { Group } 0 \\
(n=40)\end{array}$ \\
\hline Age (in yrs.) Mean \pm SD & $59.15 \pm 8.92$ & $58.6 \pm 9.43$ & $55 \pm 5.16$ \\
\hline Male & 32 & 4 & 31 \\
\hline Female & 8 & 16 & 9 \\
\hline Smoking History (Pack yrs) & 27 & Nil & Nil \\
\hline Biomass Exposure (yrs) & Nil & 32 & Nil \\
\hline FEV1 $(\mathrm{ml})$ & 845 & $\begin{array}{|ll|}753.75 & 1373.875 \\
\end{array}$ & \\
\hline $\mathrm{FVC}(\mathrm{ml})$ & 1611 & 1373.87 & \\
\hline FEV1/ FVC \% & 57 & 44.483193 & \\
\hline FEV1\% of predicted value & 44.1 & 44.48 & \\
\hline GOLD stage of airflow limitation & & 3 & \\
\hline \multicolumn{4}{|c|}{$\begin{array}{l}\text { Table 1. Distribution Pattern for Age, Sex, Smoking History, Biomass } \\
\text { Exposure and COPD Levels among Cases and Controls }\end{array}$} \\
\hline
\end{tabular}

\begin{tabular}{|c|l|c|c|c|}
\hline \multicolumn{2}{|c|}{ Groups } & $\begin{array}{c}\text { MDA } \\
(\mathbf{n m o l} / \mathbf{m l})\end{array}$ & $\begin{array}{c}\text { SOD } \\
\text { (units/gm of Hb) }\end{array}$ & $\begin{array}{c}\text { GSH } \\
(\boldsymbol{\mu m o l} / \mathbf{g m} \text { of Hb) }\end{array}$ \\
\hline Smokers & Mean & $58.0892 \pm$ & $1123.3922 \pm$ & $7.9755 \pm$ \\
(Group 1: $\mathrm{n}=40)$ & \pm S.D. & 52.53836 & 301.24220 & 2.70204 \\
\hline Biomass & Mean & $35.8219 \pm$ & $1147.0161 \pm$ & $9.6113 \pm$ \\
(Group 2:n=20) & \pm S.D. & 23.73494 & 200.58413 & 2.09725 \\
\hline Control & Mean & $15.3705 \pm$ & $1315.2305 \pm$ & $8.2895 \pm$ \\
(Group 0: $\mathrm{n}=40)$ & \pm S.D. & 6.67772 & 209.16684 & 1.08898 \\
\hline \multicolumn{6}{|c|}{ Table 2. Mean Serum Levels for MDA, SOD and GSH among } \\
Cases and Controls
\end{tabular}

\begin{tabular}{|c|c|c|c|c|c|}
\hline F-test of ANOVA & Sum of Squares & df & Mean Square & F & Sig. \\
\hline Between Groups & 39760814.19 & 2 & 19880407.099 & 699.36 & .000 \\
\hline Within Groups & 4349244.795 & 153 & 28426.437 & & \\
\hline Total & $\mathbf{4 4 1 1 0 0 5 8 . 9 9}$ & 155 & & & \\
\hline Table 3A. Comparison Between and within Case Groups and Controls \\
\hline
\end{tabular}

\begin{tabular}{|c|c|c|c|c|c|}
\hline \multicolumn{6}{|c|}{ Multiple Comparisons Post-hoc ANOVA with Bonferroni Correction } \\
\hline $\begin{array}{c}\text { Dependent } \\
\text { Variable }\end{array}$ & $\begin{array}{c}(\mathbf{X}) \\
\text { Grouping }\end{array}$ & $\begin{array}{c}\text { (Y) } \\
\text { Grouping }\end{array}$ & $\begin{array}{c}\text { Mean } \\
\text { Difference } \\
(\mathbf{X}-Y)\end{array}$ & $\begin{array}{c}\text { Std. } \\
\text { Error }\end{array}$ & $\begin{array}{c}\text { Level of } \\
\text { Significance } \\
\text { (p Value) }\end{array}$ \\
\hline \multirow{2}{*}{ MDA } & 0 vs & 1 & $-42.71867^{*}$ & 7.86790 & .000 \\
\cline { 3 - 6 } & 0 vs & 2 & -20.45145 & 9.63617 & .109 \\
\cline { 3 - 6 } & 1 vs & 2 & 22.26722 & 9.63617 & .069 \\
\hline \multirow{3}{*}{ SOD } & 0 vs & 1 & $191.83835^{*}$ & 55.65845 & .003 \\
\cline { 3 - 6 } & 0 vs & 2 & $168.21445^{*}$ & 68.16740 & .046 \\
\cline { 3 - 6 } & 1 vs & 2 & -23.62390 & 68.16740 & 1.000 \\
\hline \multirow{3}{*}{ GSH } & 0 vs & 1 & .31405 & .46227 & 1.000 \\
\cline { 3 - 6 } & 0 vs & 2 & -1.32180 & .56616 & .065 \\
\cline { 3 - 6 } & 1 vs & 2 & $-1.63585^{*}$ & .56616 & .014 \\
\hline
\end{tabular}

Table 3B. Comparison for MDA, SOD and GSH among Case Groups and Controls

Comparison of different oxidative stress markers in three study groups

The mean difference is significant at the $<0.05$ level

Control group $=0(\mathrm{X})$, Smokers with $\mathrm{COPD}=$ group $1(\mathrm{Y})$, Biomass exposed $\mathrm{COPD}=$ group2 $(\mathrm{Y})$

$(\mathrm{X}-\mathrm{Y})$ : Difference between mean values between cases and controls and those between the two case groups. Abbreviation- vs: Versus

\begin{tabular}{|c|c|c|}
\hline Parameters & r Value & p Value \\
\hline FEV1\%: MDA & -.061 & .711 \\
\hline FEV1\%: SOD & .383 & .015 \\
\hline FEV1\%: GSH & .148 & .368 \\
\hline MDA: SOD & .023 & .886 \\
\hline MDA: GSH & -.181 & .263 \\
\hline SOD: GSH & .356 & .024 \\
\hline Table 4. Pearson's Correlation Between MDA, SOD, GSH and \\
FEV1\% in COPD Cases with History of Smoking Tobacco \\
\hline
\end{tabular}

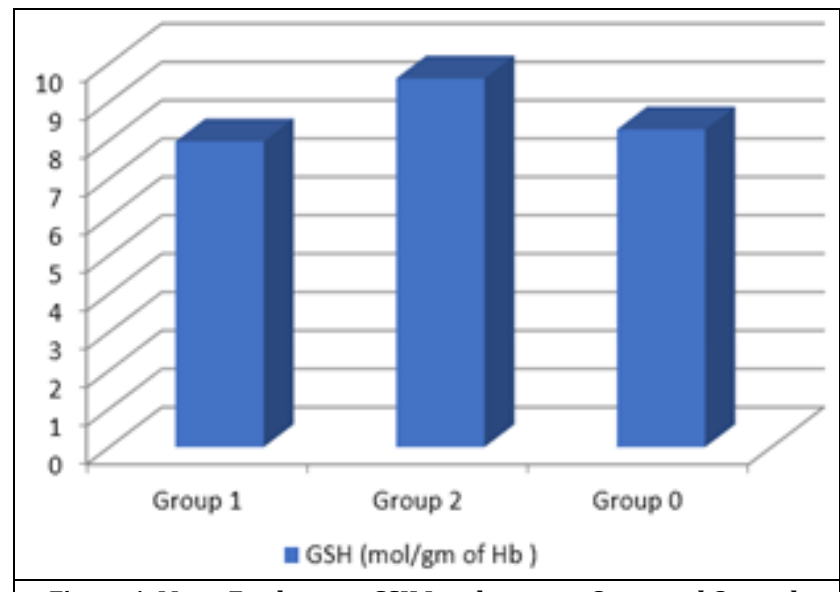

Figure 1. Mean Erythrocyte GSH Levels among Cases and Controls

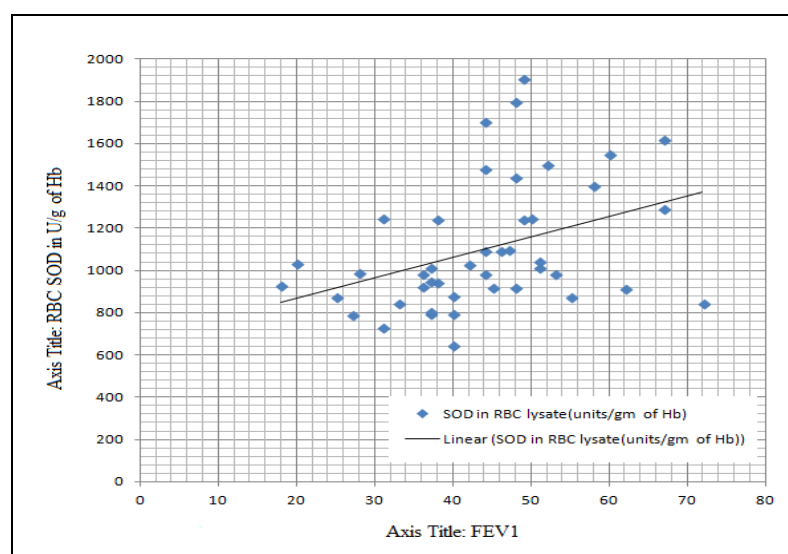

Figure 2. Scatter Graph of Correlation Between SOD and FEV1\% in COPD Cases with History of Tobacco Smoking 


\section{DISCUSSION}

Serum MDA levels alteration among smokers and biomass exposed subjects: It is known that oxidative stress is a major pathogenic component of airway inflammation that is characteristic of COPD. [20] Oxidative radicals cause damage to cellular components including membrane lipids, protein, carbohydrate and DNA.[21] It is well known that both cigarette and biomass exposure causes COPD in which free radicals and ROS increase.[22],[23] In this study, we found that plasma MDA level, an indicator of lipid peroxidation was higher in both smoking and biomass exposed COPD compared to healthy controls. PUFA and Fatty acids are major targets for free radical attack, resulting in lipid peroxidation, that continues as a chain reaction.[24] It had been shown that the levels of MDA, produced due to lipid peroxidation reaction in plasma are correlated inversely with the FEV1 percent in a population study.[25] There are reports indicating increased MDA level in both cigarette smoking and biomass exposure.[25] It is reported that there is significant decrease in antioxidant enzyme activity in females exposed to biomass fuel.

\section{Depleted SOD Stores in COPD}

SOD functions as a scavenger of $\mathrm{O}_{2}$. Radical in the body. The level of SOD is decreased in oxidative stress which plays an important role in pathogenesis of various diseases including COPD.[26] Studies of Raghunath R Rai et al,[26]Nagaraj et al[27] and Ahmad A et al[28] showed decreased level of SOD amongst patients with COPD. This is in accordance to our study results. However, Montano et al[25] have found increased SOD levels in COPD patients compared to healthy controls. These alterations in antioxidant enzymes such as SOD emphasize to redox imbalance in COPD patients. Mechanism involved in variable SOD activity is due to increased production of free radicals in COPD patients resulting in increased SOD biosynthesis as a protective mechanism as well as its increased consumption, leading to depleted intracellular levels.

\section{GSH Level Variability among Cases}

Under non-stress condition, most of the intracellular glutathione is stored in reduced form (GSH). During increased oxidative stress by tobacco smoke or biomass, the free sulfhydryl (-SH) groups become oxidized resulting in loss of GSH. The gaseous phase of cigarette smoke irreversibly reacts with GSH to form GSH derivatives which cannot be reduced back, thus depleting the total GSH pool.[29] In our study, GSH among biomass exposed COPD was statistically higher than tobacco smokers with COPD ( $\mathrm{p}$ value $<0.02$ ). Toth and colleagues (1986) stated that RBC glutathione plays a prominent role in detoxification of hydrogen peroxide $\left(\mathrm{H}_{2} \mathrm{O}_{2}\right)$. Increased GSH in RBC of COPD patients is presumably due to constant exposure to oxidative stress, resulting in induction of protein synthesis. ${ }^{[30]}$ However the activities of glutathione synthesis and redox system enzymes like glutathione peroxidase (GPx) and glucose-6-phosphate dehydrogenase (G6PD), gamma-glutamyl cysteine synthetase are transiently decreased in alveolar epithelial cells after chronic exposure to cigarette smoke condensate. This is due to action of highly electrophilic free radicals on the active sites of these enzymes, thus there is a time-dependent depletion of intracellular soluble GSH.[31] Studies had also shown a gradual age dependent decrease in serum glutathione levels among smokers.[32]

\section{High Pathogenicity of Tobacco Smoke in Causing COPD}

Studies have shown tobacco smoke induced COPD was associated with worse emphysema index in HRCT compared to biomass exposed COPD. This suggests tobacco smoke is more aggressive and leads to more parenchymal destruction than other forms of inhaled toxins.[32] Much in the same way our study explains lower GSH levels in tobacco smoke induced COPD cases compared to biomass exposed COPD cases.

\section{Exposure to Both Tobacco Smoke and Biofuels Cause COPD}

These results indicate the role of oxidative stress in causing COPD associated with tobacco smoke and inhalation of toxin for multiple hours per day, during use of solid biomass fuel for cooking food, a trend and a job done mostly by females all across India. ${ }^{[33]}$ Since unlike contents of tobacco smoke the details of various chemicals present in commonly used biofuels in rural India are yet not analyzed their individual mechanism as oxidants in pathogenesis of COPD requires further investigation.

\section{CONCLUSIONS}

Our study confirmed the presence of an oxidant-antioxidant imbalance in COPD subjects supporting the concept of systemic oxidative stress in this condition.

\section{ACKNOWLEDGEMENT}

The authors wish to convey their gratitude Dr. Subir Kumar Dey, Former Professor and Head of the Department, Dept. of Pulmonary Medicine, Calcutta National College, Kolkata, West Bengal.

\section{REFERENCES}

[1] Global strategy for diagnosis, management, and prevention of COPD. Global initiative for chronic obstructive lung disease (GOLD). [Cited 2014 January]. http://www.goldcopd.org.

[2] COPD predicted to be third leading cause of death in 2030. Geneva: Global alliance against chronic respiratory disease, WHO statistics 2008. [Cited 2008 May http://www.who.int/gard/news_events/World_Health_ Statistics_2008/en/

[3] Jindal SK, Aggarwal AN, Chaudhry K, et al. A multicentric study on epidemiology of chronic obstructive pulmonary disease and its relationship with tobacco smoking and environmental tobacco smoke exposure. Indian J Chest Dis Allied Sci 2006;48(1):23-9. 
[4] Jindal SK, Aggarwal AN, Gupta D. A review of population studies from India to estimate national burden of chronic obstructive pulmonary disease and its association with smoking. Indian J Chest Dis Allied Sci 2001;43(3):139-47.

[5] Salvi SS, Barnes PJ. Chronic obstructive pulmonary disease in non-smokers. Lancet 2009;374(9691):733-43.

[6] MacNee W. Pathogenesis of chronic obstructive pulmonary disease. Proc Am Thorac Soc 2005;2(4):25866.

[7] MacNee W, Rahman I. Is oxidative stress central to the pathogenesis of chronic obstructive pulmonary disease? Trends Mol Med 2001;7(2):55-62.

[8] Rajendrasozhan S, Yang SR, Edirisinghe $I$, et al. Deacetylases and NF-kappa B in redox regulation of cigarette smoke induced lung inflammation: epigenetics of pathogenesis of COPD. Antioxid Redox Signal 2008;10(4):799-811.

[9] Sadeghi-Hashjin G, Folkerts G, Henricks PA, et al. Peroxynitrite induces airway hyperresponsiveness in guinea pigs in vitro and in vivo. Am J Respir Crit Care Med 1996;153(5):1697-701.

[10] Rahman I, Gilmour PS, Jimenez LA, et al. Oxidative stress and TNF-alpha induce histone acetylation and NF$\mathrm{\kappa b} / \mathrm{AP}-1$ activation in alveolar epithelial cells: potential mechanism in gene transcription in lung inflammation. Mol Cell Biochem 2002;234-235(1-2):239-48.

[11] Ji C, Amarnath V, Pietenpol JA, et al. 4-hydroxynonenal induces apoptosis via caspase-3 activation and cytochrome C release. Chem Res Toxicol 2001;14(8):1090-96.

[12] Murray RK. Red \& White blood cells. In: Murray RK, Granner DK, Mayes PA, et al. eds. Harper's Illustrated Biochemistry. 26 th edn. India: McGraw-Hill Companies Inc., 2003;52:609-13.

[13] Lakari E, Paakko P, Kinnula VL. Manganese superoxide dismutase, but not CuZn superoxide dismutase, is highly expressed in the granulomas of pulmonary sarcoidosis and extrinsic allergic alveolitis. Am J Respir Crit Care Med 1998;158(2):589-96.

[14] Smith LJ, Houston M, Anderson J. Increased levels of glutathione in bronchoalveolar lavage fluid from patients with asthma. Am Rev Respir Dis 1993;147(6 Pt 1):14614.

[15] Cavalcante A, De Bruin PF. The role of oxidative stress in COPD: current concepts and perspectives. J Bras Pneumol 2009;35(12):1227-37.

[16] Owen CA. Proteinases and oxidants as targets in the treatment of chronic obstructive pulmonary disease. Proc Am Thorac Soc 2005;2(4):373-85.

[17] Devasagayam TPA, Boloor KK, Ramasarma T. Methods for estimating lipid peroxidation: an analysis of merits and demerits. Indian Journal of Biochemistry \& Biophysics 2003;40(5):300-8.

[18] Marklund S, Marklund G. Involvement of the superoxide anion radical in the autoxidation of pyrogallol and a convenient assay for superoxide dismutase. European Journal of Biochemistry 1974;47(3):469-74.
[19] Beutler E, Duron O, Kelly BM. Improved method for the determination of blood glutathione. J Lab Clin Med 1963;61:882-8.

[20] Repine JE, Bast A, Lankhorst I. Oxidative stress in chronic obstructive pulmonary disease. Oxidative Stress Study Group. Am J Respir Crit Care Med 1997;156(2 Pt 1):34157.

[21] Halliwell B. Oxidant and human disease: some new concepts. FASEB J 1987;1(5):358-64.

[22] American Thoracic Society. Standards for the diagnosis and care of patients with chronic obstructive pulmonary disease. Am J Respir Crit Care Med 1995;152(5 Pt 2):S77-121.

[23] Smith KR, Aggarwal AL, Dave RM. Air pollution and rural biomass fuels in developing countries: a pilot village study in India and implications for research and policy. Atmospheric Environment 1983;17(11):2343-62.

[24] Ceylan E, Kocygit A, Gencer M, et al. Increased DNA damage in patients with chronic obstructive pulmonary disease who had once smoked or been exposed to biomass. Respiratory Medicine 2006;100(7):1270-6.

[25] Montano M, Cisneros J, Ramirez-Venegas A, et al. Malondialdehyde \& superoxide dismutase correlate with FEV (1) in patients with COPD associated with wood smoke exposure and tobacco smoking. Inhal Toxicol 2010;22(10):868-74.

[26] Rai RR, Phadke MS. Plasma oxidant-antioxidant status in different respiratory disorders. Indian J Clin Biochem 2006;21(2):161-4.

[27] Nagaraj, Chandrakanth KH, Anand P, et al. Oxidative stress and antioxidant status in chronic obstructive pulmonary disease patients. IJPBS 2011;1(4):447-56.

[28] Ahmad A, Shameem M, Husain Q. Altered oxidantantioxidant levels in the disease prognosis of chronic obstructive pulmonary disease. International Journal of Tuberculosis \& Lung Diseases 2013;17(8):1104-9.

[29] Van der Toorn M, Smit-de Vries MP, Slebos DJ, et al. Cigarette smoke irreversibly modifies glutathione in airway epithelial cells. Am J Physiol Lung Cell Mol Physiol 2007;293(5):L1156-62.

[30] McCord JM, Fridovich I. Superoxide dismutase. An enzymic function for erythrocuprein (hemocuprein). J Biol Chem 1969;244(22):6049-55.

[31] Rahman I, MacNee W. Oxidant/antioxidant imbalance in smokers and chronic obstructive pulmonary disease. Thorax 1996;51(4):348-50.

[32] Bizoń A, Milnerowicz H. Effect of tobacco smoking on glutathione concentration in the blood. Przegl Lek 2012;69(10):809-11.

[33] Brashier B, Kajale S, Tambe S, et al. High resolution CT scan (HRCT) thorax, differences between biomass smoke exposure induced COPD (BM COPD) and tobaccosmoking COPD (TS COPD). Eur Respir J 2012;40:P268. 